\title{
Amblyopia: the need for a new approach?
}

\author{
R. M. INGRAM \\ From the Kettering and District General Hospital, Kettering
}

SUMMARY Follow-up of a series of 221 children identified by the present methods of screening, and presenting consecutively with squint and/or amblyopia, shows that there has been no demonstrable improvement in the overall incidence and severity of amblyopia 3 or more years later. A new approach to the problem is required, and this might be based on the identification and treatment of amblyopia during the 'sensitive period'.

A primary purpose of treating childhood visual disorders is reduction of the incidence and severity of amblyopia. This is a review of the overall results of treating an unselected sample of children. Although limited in content, they clearly point to the need for a fundamental change in our management of the problem.

\section{Patients and methods}

The children surveyed are an unselected group who attended the ophthalmic clinics of the Kettering district for the first time between 1 November 1971 and 31 October 1972. Their presenting features have already been reported (Ingram, 1977).

Amblyopia was recorded as the difference between the visual acuity of a pair of eyes when this was measured on a Linear Sheridan-Gardiner or Snellen chart. The total number of attendances for each child were also recorded on a master chart.

\section{Results}

Table 1 shows the number of children who were known to have amblyopia in each age group at the time they presented. In some cases, recorded as (?) amblyopia, there were grounds for suspecting amblyopia although the actual acuities were not known.

Table 2 shows the number of children and their amblyopia 3 or more years later. For ease of comparison they are recorded according to the age at which they presented. There are 5 more children in this Table, because 2 were 'missed' off the original charts which formed the basis for Table 1 and other publications (Ingram, 1977; Ingram et al.,

Address for reprints: Dr R. M. Ingram, Kettering and District General Hospital, Rothwell Road, Kettering, Northamptonshire NN16 8UZ
Table 1 Amblyopia at the time the children presented

\begin{tabular}{|c|c|c|c|c|c|c|c|c|c|c|}
\hline $\begin{array}{l}\text { Age of } \\
\text { presentation }\end{array}$ & Amblyopia: & 0 & $<1$ & $<2$ & $<3$ & $<4$ & $<5$ & $5+$ & $-?$ & Total \\
\hline $0-1$ & & 2 & - & - & - & - & - & 1 & 6 & 9 \\
\hline $1-2$ & & 3 & - & - & - & - & - & -1 & 11 & 14 \\
\hline $2-3$ & & 2 & - & - & 2 & - & - & 1 & 11 & 16 \\
\hline $3-4$ & & 9 & 5 & 2 & 2 & - & - & 5 & 2 & 25 \\
\hline 4-5 & & 6 & - & 3 & 1 & - & - & 1 & 1 & 12 \\
\hline $5-6$ & & 14 & 5 & 6 & 6 & 2 & 3 & 6 & 6 & 48 \\
\hline $6-7$ & & 4 & 4 & 6 & 5 & - & 1 & 3 & 5 & 28 \\
\hline $7-8$ & & 5 & 3 & 1 & 4 & 2 & - & 2 & 3 & 20 \\
\hline $8+$ & & 10 & 6 & 5 & 10 & 10 & 2 & 5 & 1 & 49 \\
\hline Total & & 55 & 23 & 23 & 30 & 14 & 6 & 24 & 46 & 221 \\
\hline
\end{tabular}

1977), and 3 children were originally thought to be normal but were eventually found to have esotropia and/or amblyopia. Those who were considered too old for treatment when they presented were not reexamined, and it has been assumed, perhaps wrongly, that their vision has not altered significantly.

We knew the initial and final visual acuity of 91 of those children who attended reasonably regularly for treatment. The details of these children have been reported (Ingram et al., 1977) (Tables 1 and 2), but they are summarised in Table 3.

\section{Discussion}

Chavasse (1932) said: 'I think the time has come for us to admit, to ourselves at all events, that the treatment of these cases is, in the bulk, unsatisfactory'. He was talking about squint, but the same could also be said about our treatment of amblyopia. A large number of outpatient attendances have resulted in no overall reduction in the incidence or severity of amblyopia in this district. Nobody could 
Table 2 Amblyopia $3 \frac{1}{2}$ years after initial presentation

\begin{tabular}{|c|c|c|c|c|c|c|c|c|c|c|c|}
\hline $\begin{array}{l}\text { Age of } \\
\text { presentation }\end{array}$ & Amblyopia: & 0 & $<1$ & $<2$ & $<3$ & $<4$ & $<5$ & $5+$ & $?$ & Total & \\
\hline $0-1$ & & 2 & 1 & 1 & - & - & - & 2 & 5 & 11 & 2 missed off original \\
\hline $1-2$ & & 2 & - & 1 & 4 & - & 1 & 1 & 6 & 15 & 1 developed squint \\
\hline $2-3$ & & 4 & 2 & - & 2 & 1 & 3 & 4 & - & 16 & \\
\hline $3-4$ & & 6 & 4 & 6 & 3 & 2 & 4 & - & 1 & 26 & $\begin{array}{l}1 \text { extra found to be } \\
\text { amblyopic }\end{array}$ \\
\hline $4-5$ & & 7 & - & 3 & 1 & - & 1 & - & - & 12 & \\
\hline $5-6$ & & 4 & 4 & 17 & 9 & 4 & 6 & 4 & 1 & 49 & 1 missed off original \\
\hline $6-7$ & & 2 & 6 & 6 & 5 & 2 & 一 & 4 & 3 & 28 & \\
\hline $7-8$ & & 4 & 5 & 1 & 4 & 1 & 2 & 1 & 2 & 20 & \\
\hline $8+$ & & 11 & 6 & 4 & 9 & 11 & 2 & 5 & 1 & 49 & \\
\hline Total & & 42 & 28 & 39 & 37 & 21 & 19 & 21 & 19 & 226 & \\
\hline
\end{tabular}

Table 3 Initial and final visual acuity

\begin{tabular}{lccccccc}
\hline Amblyopia : & 0 & $<1$ & $<2$ & $<3$ & $<4$ & $<5$ & $5+$ \\
\hline Initial & 27 & 11 & 15 & 17 & 4 & 2 & 15 \\
3+ years later & 13 & 14 & 26 & 18 & 5 & 9 & 6
\end{tabular}

21 hat $>3$ lines of amblyopia initially, and 20 had this degree of amblyopia 3 + years later

claim that identification and treatment of these particular children has been effective or efficient, and it is important not to overlook the distress and inconvenience caused to individual parents and children by unnecessary hospital attendances.

On the other hand we cannot simply dismiss our present methods of treatment because we do not know how many of those children presenting now would have deteriorated to severe (secondary?) amblyopia if they had not been treated. This is our dilemma. Occlusion is the standard treatment for amblyopia, but we use it more in the hope that it will reduce amblyopia than in the certain knowledge that it will cure. In practice the problem is when to stop it.

We found that occlusion consistently reduced the amount of amblyopia in only a small group of 15 of these children, all of whom presented with severe amblyopia and none of whom were cured (Ingram et al., 1977). We have suggested that it is effective only in the reduction of amblyopia secondary to relatively long-standing squint (Ingram et al., 1977). More specifically, we seem to be incapable of improving what we have called 'primary' amblyopia. Possibly this is because (see, for example, Breinin (1973)) occlusion is most often used after the end of the 'sensitive period' identified in animals (Hubel and Wiesel, 1970; Blakemore and van Sluyters, 1974). If this is so, then we need to clarify the duration of the 'sensitive period' in man in order that treatment may be given at a time when it might be effective.
Chavasse (1932) also said: 'A satisfactory understanding of the nature of squint is of primary importance'. The animal experiments started by Hubel and Wiesel may provide this, but whether squint and amblyopia are the result of an inborn neurological abnormality or an environmental factor such as blurred vision during the sensitive period (Whitteridge, 1977) is still disputed.

The fact that these children made 1487 return attendances to the clinic is a measure of the time and money spent in the doubtful improvement of a condition that had probably been established long before any defect was identified. Clearly, there is scope here for redistribution of resources in the search for more effective management of the problem. Chavasse (1932) regarded it as 'A problem of the public health', and, if this is correct, we must ultimately aim to devise a means of prevention. Screening is regarded as the key to this. For clinicians the problem is when should we screen and what should we look for?

\section{References}

Blakemore, C., and van Sluyters, R. C. (1974). Reversal of the physiological effects of monocular deprivation in kittens. Journal of Physiology, 237, 195-216.

Breinin, G. M. (1973). In discussion of paper by von Noorden, G. K., on experimental amblyopia in monkeys. Transactions of the American Ophthalmological Society, 71, 124.

Chavasse, B. (1932). In symposium on non-paralytic squint. Transactions of the Ophthalmological Societies of the United Kingdom, 52, 348-352.

Hubel, D. H., and Wiesel, T. N. (1970). The period of susceptibility to the physiological effects of unilateral eye closure in kittens. Journal of Physiology, 206, 419-436.

Ingram, R. M. (1977). The problem of screening children for visual defects. British Journal of Ophthalmology, 61, 4-7.

Ingram, R. M., Rogers, S., and Walker, C. (1977). Occlusion and amblyopia. British Orthoptic Journal, 34, 11-22.

Whitteridge, D. (1977). The cortical contribution to binocular vision. Transactions of the Ophthalmological Societies of the United Kingdom, 97, 39-47. 